\title{
Determination of Biochemical Contents of Fresh, Oven-Dried, and Sun-Dried Peels and Pulps of Five Apple Cultivars (Amasya, Braeburn, Golden Delicious, Granny Smith, and Starking)
}

\author{
Zeynep Ergün (D) \\ Department of Bioengineering, Adana Alparslan Türkeş Science and Technology University, Adana 01250, Turkey \\ Correspondence should be addressed to Zeynep Ergün; zergun@atu.edu.tr
}

Received 12 March 2021; Revised 16 April 2021; Accepted 19 May 2021; Published 25 May 2021

Academic Editor: Philippe Jeandet

Copyright (c) 2021 Zeynep Ergün. This is an open access article distributed under the Creative Commons Attribution License, which permits unrestricted use, distribution, and reproduction in any medium, provided the original work is properly cited.

\begin{abstract}
This study aimed to investigate the biochemical compounds of five different apple cultivars (Amasya, Braeburn, Golden Delicious, Granny Smith, and Starking) grown in the same location and to reveal the differences between peel and pulp in the fresh, ovendried, and sun-dried samples. Sugar and organic acid contents were analyzed through high-performance liquid chromatography. Besides, antioxidant activity, total flavonoid, and total phenolic contents were analyzed with a spectrophotometer. The results of these analyses showed that the compounds varied between peel and pulp and among fresh, oven-dried, and sun-dried samples. The largest level of total flavonoid was found in Amasya oven-dried peel, and the largest total phenol, antioxidant activity, fructose, and total sugar levels were observed in Amasya sun-dried peel. Moreover, the largest L-ascorbic acid was detected in Amasya oven-dried pulp. Granny Smith oven-dried pulp was rich in citric, succinic acids, and glucose. Braeburn sun-dried pulp, Golden Delicious oven-dried pulp, and Granny Smith sun-dried pulp contained the largest sucrose, malic acid, and total soluble solids levels, respectively. For data interpretation, $t$-test, ANOVA, Duncan's test, Kruskal-Wallis $\mathrm{H}$ test, and principal component analysis were performed. The peel contained significantly higher total flavonoid, total phenol, and antioxidant activity than pulp. Moreover, among fresh, oven-dried, and sun-dried samples, total phenol, succinic acid, malic acid, and L-ascorbic acid significantly differed. As a whole, the pulp was rich in sugars. The results provide valuable information on the food quality parameters of five different apple cultivars. It was demonstrated that consuming apple with its peel is healthier (in terms of total flavonoid, total phenol, antioxidant activity parameters, and L-ascorbic acid), and drying (especially the sun-drying method) is an effective food storage method for apples.
\end{abstract}

\section{Introduction}

Fruits are one of the main nutrition sources in the daily human diet. The quality of the fruits has a substantial effect on the decision-making process of the consumers. Biochemical characteristics are ranked among the inner-quality determiners of fruits, as well as increasing outer quality. This study aims to reveal the biochemical characteristics of five different apple cultivars and to make a comparison between fresh, open-air-dried, and oven-dried peel and pulp samples of these varieties. This study focuses on the parameters of total phenols, total flavonoids, sugars, organic acids, and total soluble solids (TSS) among other biochemical characteristics.
Apple (Malus domestica Borkh.) is one of the members of the Rosaceae family and has been consumed by humans since the early ages. It is one of the most frequently consumed fruits [1]. In addition to its low-calorie levels and high levels of water and fiber, containing essential vitamins, minerals, and trace elements makes the apple a healthy fast food. Phenols, pectin, sugar, acids, and antioxidants containing in apples generally have positive effects on human health [2-4]. Some diseases such as cancer, cardiovascular disease, asthma, and diabetes can be prevented through some biochemical compounds of apple [5-8]. The absorption of gastric secretions, elimination of toxins, and having a diuretic effect are some of the benefits of apple to human health [9]. Besides the health benefits, the apple is an 
important economic value. According to the FAO data [10], the five largest apple producers can be listed as China, the USA, Turkey, Poland, and India. These countries produced nearly $65 \%$ of apples in the world in 2019. In terms of exporting, China, the USA, Italy, Chile, and New Zealand were the largest apple sellers in the same year.

Biochemical compounds of apples determine the quality in terms of not only health but also the economy. Biochemical parameters of apples may be influenced by species, varieties, cultivation conditions, and cultivation techniques [11-15]. Most of the antioxidant activities in apples were fulfilled by polyphenolic antioxidants [16]. Apple peel contains significantly high amounts of polyphenolic compounds in comparison with apple pulp or cores $[8,13,17,18]$. Total antioxidant activity and phenolic content [16, 19-22] and L-ascorbic acid content [20, 23, 24] may depend on the apple cultivars. Similarly, sugar and acid contents [9], total phenolic levels $[25,26]$, and TSS [1, 25] also vary between cultivars of apples. Moreover, drying methods may affect some biochemical contents [18]. It is important to determine these parameters due to their impact on apple quality.

The novelty of this research comes especially from the investigation of some biochemical compounds through the implementation of different drying methods for the pulp and peel of five different apple varieties. To the best of the author's knowledge, this is the first study focusing on differences of the total phenol, total flavonoid, sugars, organic acids, TSS, and antioxidants levels of fresh, traditionally open-air-sun-dried, and oven-dried pulp and peel. This is important since apples are consumed peeled and unpeeled. The cultivars used in this study are Amasya, Granny Smith, Braeburn, Starking, and Golden Delicious grown in Isparta, Turkey.

The remainder of this paper is organized as follows: in the second section, the material and methodology are introduced. In the third section, the results are presented and discussed in light of the previous studies. Finally, in the fourth section, the findings are summarized.

\section{Materials and Methods}

In this research, five apple cultivars (Amasya, Braeburn, Golden Delicious, Granny Smith, and Starking) were used grown in Isparta, Turkey. The fruits were commercially harvested in the 2020 season. The analytical parameters were measured by using mixes of 10 fruits for the cultivars. Fresh, oven-dried, and sun-dried peels and pulps of the cultivars were used for the biochemical analysis. Oven-dried samples were prepared by drying in an oven at $70^{\circ} \mathrm{C}$ for $10 \mathrm{~h}$. And, sun-dried samples were prepared by drying in open-air conditions in August for 3 days in Adana, Turkey.

2.1. Organic Acid and Vitamin C Content. Organic acid analyses were done using high-performance liquid chromatography equipped with a UV detector (Shimadzu) according to the method of Bozan et al. [27]. Organic acids were extracted by $3 \%$ metaphosphoric acid. A Transgenomic
ICSep ICE COREGEL-87H3 $(250 \mathrm{~mm} \times 4.6 \mathrm{~mm}, 5 \mu \mathrm{m})$ Organic Acid column was used (2032 San Jose, CA 95131, USA). The column temperature was adjusted to $30^{\circ} \mathrm{C}$. The mobile phase was $0.05 \%$ sulphuric acid with a flow rate of $0.6 \mathrm{~mL} / \mathrm{min}$. The organic acid content of samples was determined qualitatively and quantitatively at a wavelength of $210 \mathrm{~nm}$, while $\mathrm{C}$ vitamin content was determined at a wavelength of $242 \mathrm{~nm}$ by comparison of the external standard calibration curve and the retention time of the standard.

2.2. Individual Sugar Content. The total soluble solid (TSS) content of samples was determined using the digital hand refractometer. Individual sugar contents (glucose, fructose, and sucrose) in one gram of fresh and dried samples were detected using high-performance liquid chromatography (HPLC) (Shimadzu) equipped with a refractive index detector (RID) and Transgenomic COREGEL-87C $(250 \mathrm{~mm} \times 4.6 \mathrm{~mm}, 5 \mu \mathrm{m})$. The column temperature was adjusted to $70^{\circ} \mathrm{C}$. The mobile phase was ultra-deionized water with a flow rate of $0.6 \mathrm{~mL} / \mathrm{min}$. The sugar contents of the samples were determined qualitatively and quantitatively using the refractive index curves according to the external standard and the retention time of the standard using the refractive index detector.

2.3. Determination of Total Phenolic Compounds. The amount of total phenolics of samples was identified by the Folin-Ciocalteu reagent using the modified method of Spanos and Wrolstad [28]. $\mu \mathrm{L}$ of Folin-Ciocalteu's reagent was mixed with $50 \mu \mathrm{L}$ of methanolic extracts followed by adding $750 \mu \mathrm{L}$ of sodium carbonate $(20 \% w / v)$. The solution was incubated at room temperature in dark for 2 hours. The absorbance of all samples was measured at $760 \mathrm{~nm}$ using Multiskan $^{\mathrm{TM}}$ GO Microplate Spectrophotometer. Results were expressed as milligrams of gallic acid equivalent per gram of extract (mg/GAE100 g) [29].

2.4. Determination of Total Flavonoid Compounds. Determination of the total flavonoid content of fresh and dried samples was performed by the method of aluminum chloride colorimetric [30]. Rutin was used as the standard for the calibration curve. $200 \mu \mathrm{L}$ methanolic extract was diluted with $4600 \mu \mathrm{L}$ of ethanol and reacted with $2 \% \mathrm{AlCl}_{3}$. The solution was incubated for $45 \mathrm{~min}$ at room temperature. The absorbance of the reaction mixtures was read against a blank at $415 \mathrm{~nm}$ using Multiskan ${ }^{\mathrm{TM}}$ GO Microplate Spectrophotometer.

\subsection{Determination of DPPH Radical Scavenging Activity.} The ability of hydrogen donating or radical scavenging of samples was measured using DPPH (1, 1-diphenyl 2-picrylhydrazyl) method according to the method of BrandWilliams et al. [31]. About $1950 \mu \mathrm{L}$ of the $1 \mathrm{mM}$ solution of $\mathrm{DPPH}$ was mixed with $50 \mu \mathrm{L}$ of methanolic extract of samples. The absorbance was measured at $517 \mathrm{~nm}$ against the corresponding blank solution as $80 \%$ methanol and control. 
Percentage inhibition of radical DPPH\% inhibition was calculated based on control reading by the following equation:

$$
\begin{aligned}
\mathrm{DPPH}-\text { percentage } \% \text { of reduction power } & =\left(\left(\frac{\mathrm{Ac}-\mathrm{As}}{-\mathrm{Ac}}\right) \times 100\right), \\
\text { DPPH \% inhibition } & =\left(\left(\frac{\mathrm{Ac}-(\mathrm{As}-\mathrm{Ab})}{\mathrm{Ac}}\right)\right) \times 100,
\end{aligned}
$$

where Ac is the absorbance of the control (standard), As is the absorbance of the sample, and $\mathrm{Ab}$ is the absorbance of the blank.

2.6. Statistical Analysis. The statistics of biochemical analysis were done using independent samples $t$-test, ANOVA, Duncan's test, Kruskal-Wallis $\mathrm{H}$ test, and principal component analysis (PCA) methods. By employing independent samples $t$-test, ANOVA, Duncan's test, and Kruskal-Wallis $\mathrm{H}$ test, the differences between (1) peel and pulp samples, (2) fresh, oven-dried, and sun-dried samples, and (3) five apple cultivars were investigated. The methods were chosen due to the normal and nonnormal distribution characteristics of the data. As an output of PCA, the biplot graph is a useful tool to visualize the interrelationships between variables and observations through the generated first and second principal components (PC1 and PC2). In a biplot, which is an output of PCA, the length of the lines gives the variances of the variables. Longer lines mean higher variance. The cosine of the angle and the lines show the correlation between the variables. A closer angle to 90, or 270 degrees, means a lower correlation. A correlation of 1 or -1 is approximated by an angle of 0 or 180 degrees, respectively [32]. The PCA was performed for sugar contents data and organic acids data. For the group comparison tests and PCA, SPSS and XLSTAT software programs were employed, respectively.

\section{Results and Discussion}

3.1. Organic Acid and Vitamin C Results. Amasya oven-dried pulp, Braeburn sun-dried peel, and Granny Smith sun-dried peel were the top three and found to be rich in L-ascorbic acid contents. Unlikely, Starking fresh pulp, Starking ovendried peel, and Starking fresh peel were the last three in terms of L-ascorbic acid. While the first three citric acidcontaining samples can be listed as Granny Smith ovendried pulp, Braeburn oven-dried pulp, and Golden Delicious oven-dried pulp; Amasya fresh peel, Braeburn fresh pulp, and Golden Delicious fresh pulp were on the end of the list. Granny Smith oven-dried pulp, Braeburn sun-dried peel, and Granny Smith sun-dried peel samples were found to be the largest succinic acid-containing sample; however, Granny Smith fresh pulp, Golden Delicious fresh pulp, and Starking fresh peel samples were the minimum citric acidcontaining ones. In the malic acid content list, Granny Smith sun-dried pulp, Braeburn sun-dried pulp, and Starking sun- dried pulp were the first three, and the Golden Delicious fresh peel, Granny Smith fresh peel, and Braeburn fresh peel were the last three ones (see Table 1). The previous studies argue that the dominant organic acid is malic acid. The results of this study are nearly uniform for Granny Smith [33]. The organic acid content results differed from the former studies for Amasya [33], Granny Smith [33], Braeburn [34], Starking [35], and Golden Delicious [36, 37]. The main result of this difference might be genotypic, weather, and soil differences $[2,38]$. In total, by ignoring the cultivar differences, the smallest amounts of L-ascorbic acid, citric acid, and malic acid were observed in the fresh pulp samples, and the smallest amount of succinic acid was observed in the fresh peel samples. This may show that fresh apples contain lower acid contents. And, the largest L-ascorbic acid and citric acid were found in the sun-dried peel, and succinic acid and malic acid were found in sun-dried pulp and ovendried peel, respectively. The results, out of malic acid, may indicate that sun drying is more effective than the other methods, in terms of having higher levels of acids.

3.2. Individual Sugar Content Results. In the fresh pulp group, the largest fructose, glucose, sucrose, and total sugar levels were observed in the Amasya cultivar. And the minimum levels were observed in Braeburn, Golden Delicious, Starking, and Golden Delicious, respectively. According to the fresh peel sample, the largest and minimum fructose was found in Amasya and Braeburn, the largest and minimum glucose was found in Starking and Braeburn, the largest and minimum sucrose was found in Golden Delicious and Starking, and the largest and minimum total sugar was found in Amasya and Golden Delicious, respectively. In the oven-dried pulp group, the largest fructose, glucose, sucrose, and total sugar levels were observed in Starking, Granny Smith, Amasya, and Starking, respectively. The minimum levels were in Amasya (for fructose and glucose), Granny Smith, Braeburn, and Starking, respectively. Besides, for the oven-dried peel group, the largest fructose, glucose, sucrose, and total sugar levels were observed in the Amasya apple cultivar. And the minimum levels were observed in Granny Smith, Braeburn, Granny Smith, Braeburn, and Golden Delicious, respectively. Among the sun-dried pulp samples, the largest levels of fructose, glucose, sucrose, and total sugar were found in Golden Delicious, Starking, Braeburn, and Golden Delicious samples, respectively. On the other hand, the minimum 


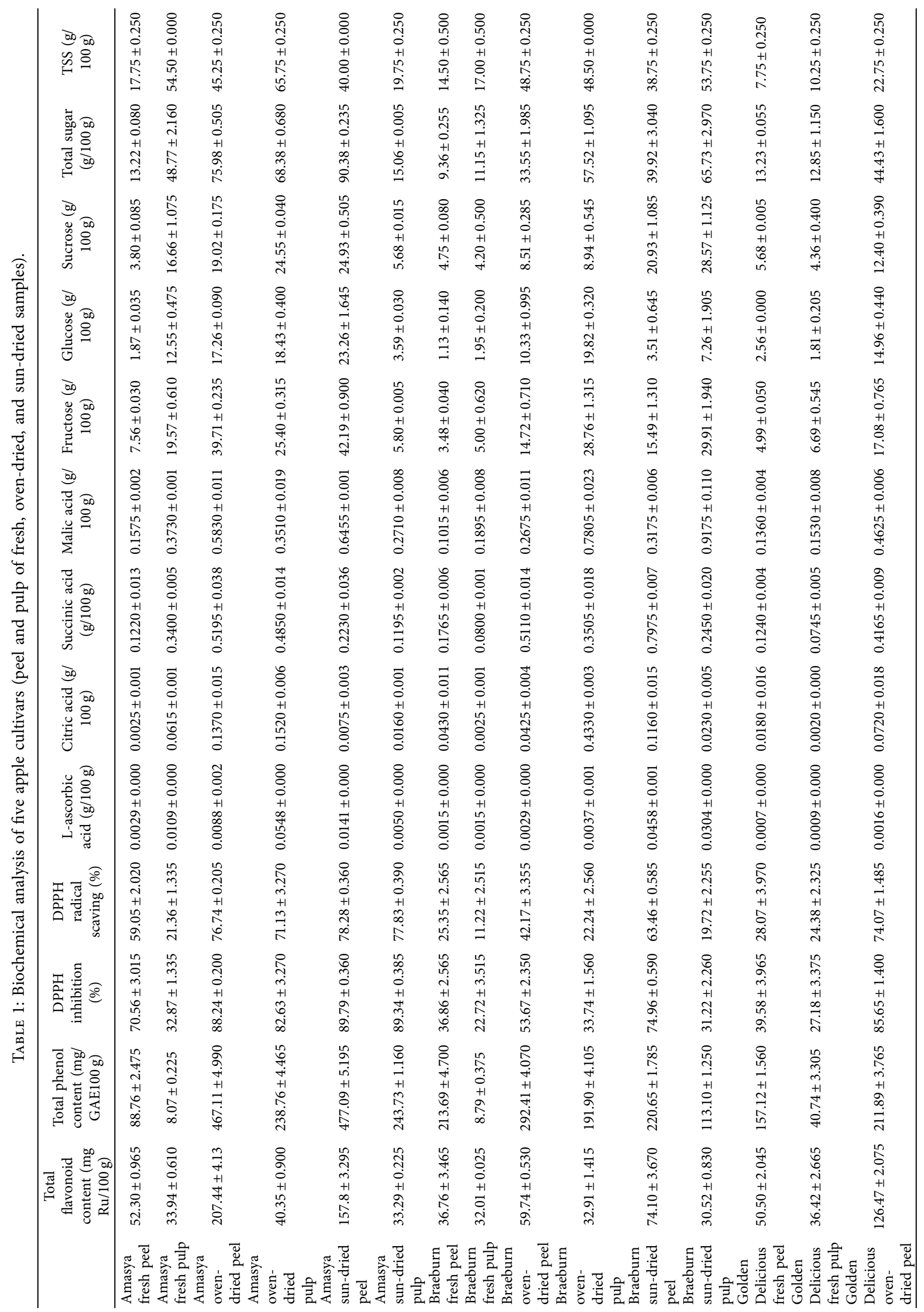




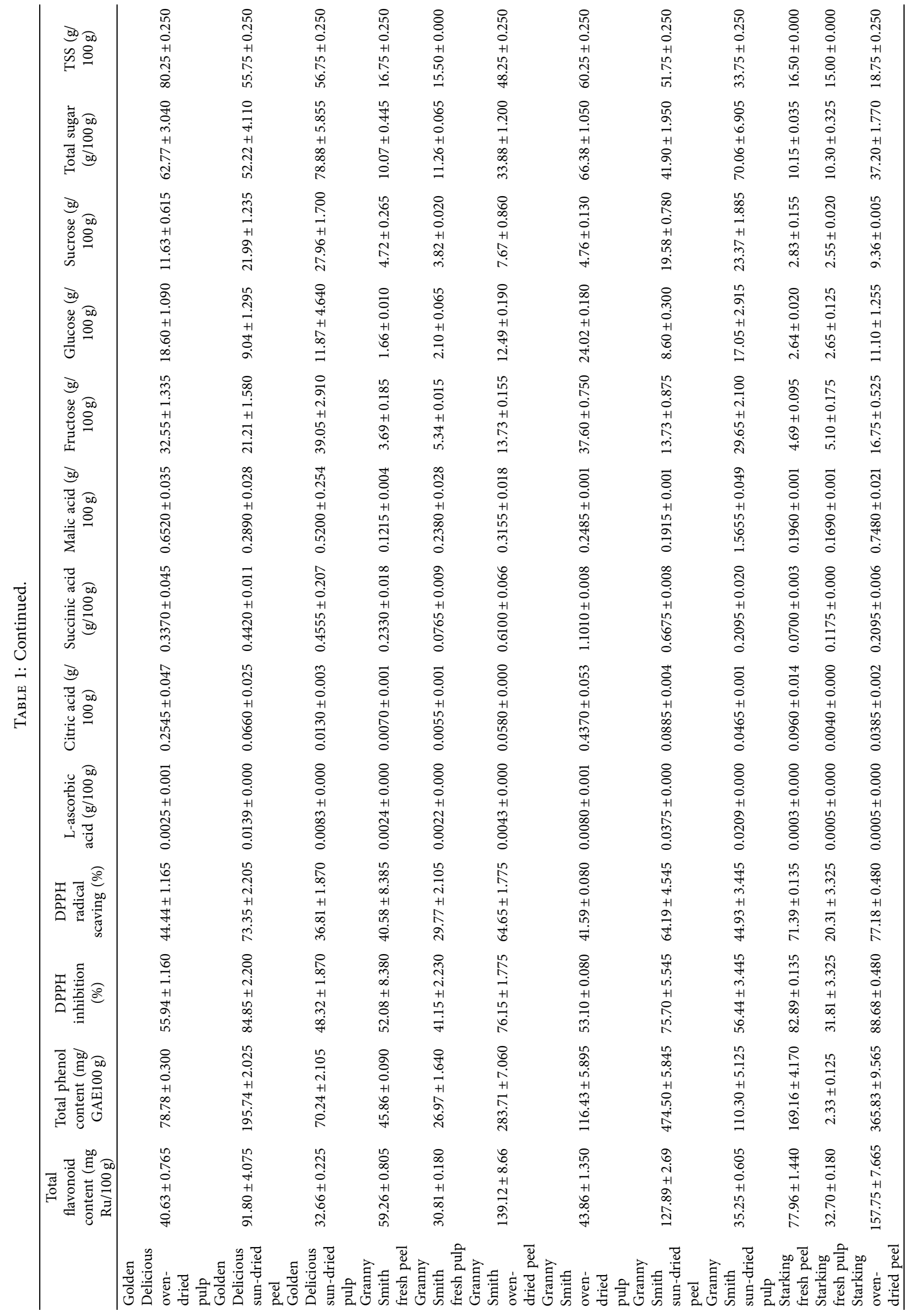




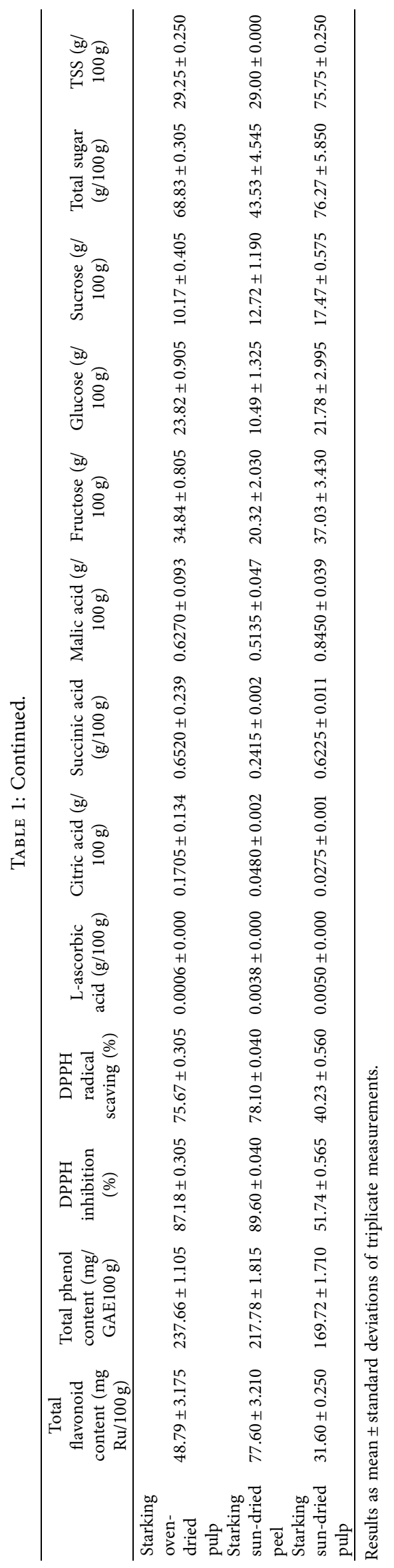


levels were observed in the Amasya sample. For the sundried peel group, the largest observations were found in Amasya, in terms of fructose, glucose, sucrose, and total sugar levels. The minimum fructose and glucose levels were detected in Granny Smith, sucrose level in Starking, and total sugar in Braeburn samples. Golden Delicious oven-dried pulp, Starking sun-dried pulp, and Amasya oven-dried pulp are the top three samples; Braeburn fresh peel, Golden Delicious fresh pulp, and Golden Delicious fresh peel are the last three samples, in terms of TSS (see Table 1). Most of the former studies are on fresh pulp or whole (peel + pulp) fresh fruit. The result of this study is parallel with those for Amasya [39], Granny Smith [40], Braeburn [34, 38, 41, 42], Starking [39], and Golden Delicious [36, 37, 39, 40]. The TSS results of this study are similar for Granny Smith and Golden Delicious [39]. The reason for the differences might be differences in cultivars, position, and exposition of the fruits in the crown, culture technology, and weather conditions [9]. In total, by ignoring the cultivar differences, while the lowest sugar content (fructose, glucose, sucrose, and total sugar) and TSS level were found in fresh peel samples, the highest levels were observed in the sun-dried pulp.

3.3. Total Phenolic Results. Amasya sun-dried peel, Granny Smith sun-dried peel, and Amasya oven-dried peel samples were found to be the first three with their phenolic contents. But, Braeburn fresh pulp, Amasya fresh pulp, and Starking fresh pulp had the lowest level of total phenolic (see Table 1). The results were parallel with previous studies, with small differences for Amasya [33], Granny Smith [20, 33, 43, 44], Braeburn [34, 41], Starking [35, 44], and Golden Delicious $[8,20,36,45,46]$. If the differences caused by the apple cultivars were neglected, the sun-dried and oven-dried peels contained the largest total phenols. But, the pulp of fresh apples contained the lowest amount.

3.4. Total Flavonoid Results. The largest levels of total flavonoid levels were observed in the samples of Amasya ovendried peel, Amasya sun-dried peel, and Starking oven-dried peel samples. On the other hand, the lowest levels were observed in the samples of Starking sun-dried pulp, Granny Smith fresh pulp, and Braeburn sun-dried pulp (see Table 1). In general, the results are similar to the literature on flavonoids in Amasya [33] and Granny Smith [33]. As the same with the literature $[8,20,36,41]$, in this study, the peels contained more total flavonoids than pulp. When the cultivar discrepancies were ignored, the flavonoid performance of oven-dried peel was the best, while sun-dried pulp was the worst.

3.5. Antioxidant Capacity Results. According to DPPH free radical scavenging capacity, the highest antioxidant activities were measured for Amasya sun-dried peel, Starking sundried peel, and Amasya sun-dried pulp samples, and the lowest levels were observed in Braeburn sun-dried pulp, Golden Delicious fresh pulp, and Braeburn fresh pulp samples. Furthermore, according to the DPPH inhibition method, the highest antioxidant activities were measured for Amasya sun-dried peel, Starking sun-dried peel, and Amasya sun-dried pulp samples. Starking fresh pulp, Braeburn sun-dried pulp, and Braeburn fresh pulp samples had the lowest level of antioxidant capacity (see Table 1). 2-5 times higher total antioxidant capacity levels were observed in the literature, in peels than pulps [11]. Although some differences with the previous studies were detected, with a general evaluation, the result of this study is similar $[8,33,41,45,46]$. By ignoring the cultivar variations, the sun-dried peel samples displayed the best performance and the lowest antioxidant capacity was observed in fresh pulps in terms of antioxidant capacity.

3.6. Statistical Results. The results of the investigation of the differentiations between pulps and peels can be seen in Table 2. According to the results, total flavonoid, total phenol, and antioxidant activity parameters differ. These are significantly high in the peel. But the rest of the parameters do not significantly differ. Additionally, some descriptive statistics, such as mean and standard deviation, were also shown in the table.

The results of the investigation of the difference among fresh, oven-dried, and sun-dried samples are shown in Tables 2 and 3. ANOVA and Kruskal-Wallis $\mathrm{H}$ test were performed according to the different characteristics of data.

Due to the normal distribution of the total flavonoid, total phenol, succinic acid, malic acid, and L-ascorbic acid, ANOVA was performed. According to results, total phenol, succinic acid, malic acid, and L-ascorbic acid differed among fresh, oven-dried, and sun-dried samples. After the results of ANOVA, to clearly see which groups significantly differ, Duncan's test was performed. The results are shown in Table 4.

Because the data of antioxidant activity parameters, citric acid, fructose, glucose, sucrose, total sugar, and TSS was not normally distributed, the Kruskal-Wallis $\mathrm{H}$ test was used to investigate the difference between being fresh, oven-dried, and sun-dried. The results are shown in Table 5. Kruskal-Wallis $\mathrm{H}$ test showed that the parameters given in Table 5 significantly differ in fresh, oven-dried, and sundried samples.

In addition to the group comparison tests of biochemical compounds, to visualize the interrelations between variables and observations, PCA was performed with organic acids (see Figure 1) and sugar data (see Figure 2). According to the PCA results of organic acids, PC1 and PC2 can explain $44.32 \%$ and $24.71 \%$ of the total variance, respectively. $69.03 \%$ of the total variance was able to be explained by the first two principal components. The correlations between variables were positive but not strong. Some certain acid levels were maximum when the samples dried in the oven or sun.

According to the PCA results of sugars, PC1 explained $83.56 \%$ of the variance, while PC2 explained $14.72 \%$. Thus, $98.28 \%$ of the total variance was able to be explained by the first two principal components. The correlations between variables were positive. Higher levels of certain sugars were observed especially in pulps. Peels had the lowest sugar, as 
TABLE 2: $t$-test results.

\begin{tabular}{|c|c|c|c|c|c|}
\hline Compounds & Sample & Mean & Std. deviation & $t$ & Prob. \\
\hline \multirow{2}{*}{ Total flavonoid } & Peel & 103.15 & 50.03 & \multirow{2}{*}{5.195} & \multirow{2}{*}{0.000} \\
\hline & Pulp & 35.71 & 5.35 & & \\
\hline \multirow{2}{*}{ Total phenol } & Peel & 270.89 & 131.21 & \multirow{2}{*}{3.896} & \multirow{2}{*}{0.001} \\
\hline & Pulp & 110.50 & 87.65 & & \\
\hline \multirow{2}{*}{ \% DPPH inhibition } & Peel & 72.76 & 18.99 & \multirow{2}{*}{3.027} & \multirow{2}{*}{0.005} \\
\hline & Pulp & 49.69 & 21.83 & & \\
\hline \multirow{2}{*}{$\% \mathrm{DPPH}$ radical scavenging } & Peel & 61.25 & 18.99 & \multirow{2}{*}{2.992} & \multirow{2}{*}{0.006} \\
\hline & Pulp & 38.77 & 21.29 & & \\
\hline \multirow{2}{*}{ Citric acid } & Peel & 0.01 & 0.01 & \multirow{2}{*}{-0.086} & \multirow{2}{*}{0.932} \\
\hline & Pulp & 0.01 & 0.01 & & \\
\hline \multirow{2}{*}{ Succinic acid } & Peel & 0.06 & 0.04 & \multirow{2}{*}{-1.197} & \multirow{2}{*}{0.242} \\
\hline & Pulp & 0.11 & 0.15 & & \\
\hline \multirow{2}{*}{ Malic acid } & Peel & 0.37 & 0.22 & \multirow{2}{*}{0.245} & \multirow{2}{*}{0.808} \\
\hline & Pulp & 0.35 & 0.28 & & \\
\hline \multirow{2}{*}{ L-ascorbic acid } & Peel & 0.35 & 0.21 & \multirow{2}{*}{-1.526} & \multirow{2}{*}{0.139} \\
\hline & Pulp & 0.53 & 0.39 & & \\
\hline \multirow{2}{*}{ Fructose } & Peel & 16.55 & 11.96 & \multirow{2}{*}{-1.317} & \multirow{2}{*}{0.199} \\
\hline & Pulp & 22.82 & 13.52 & & \\
\hline \multirow{2}{*}{ Glucose } & Peel & 9.21 & 6.53 & \multirow{2}{*}{-1.148} & \multirow{2}{*}{0.261} \\
\hline & Pulp & 12.48 & 8.58 & & \\
\hline \multirow{2}{*}{ Sucrose } & Peel & 12.50 & 7.43 & \multirow{2}{*}{-0.150} & \multirow{2}{*}{0.882} \\
\hline & Pulp & 12.98 & 9.39 & & \\
\hline Total sugar & Peel & 38.27 & 24.03 & & 0.306 \\
\hline lotal sugar & Pulp & 48.28 & 27.39 & -1.043 & 0.306 \\
\hline TSS & Peel & 32.46 & 16.22 & -1.309 & 0.201 \\
\hline & Pulp & 42.40 & 23.67 & -1.309 & \\
\hline
\end{tabular}

TABLE 3: ANOVA results.

\begin{tabular}{|c|c|c|c|c|c|}
\hline & & $\mathrm{df}$ & Mean square & $F$ & Sig. \\
\hline \multirow{3}{*}{ Total flavonoid } & Between groups & 2 & 5091.682 & \multirow{3}{*}{2.377} & \multirow{3}{*}{0.113} \\
\hline & Within groups & 26 & 2142.214 & & \\
\hline & Total & 28 & & & \\
\hline \multirow{3}{*}{ Total phenol } & Between groups & 2 & 84508.292 & \multirow{3}{*}{6.302} & \multirow{3}{*}{0.006} \\
\hline & Within groups & 26 & 13408.715 & & \\
\hline & Total & 28 & & & \\
\hline \multirow{3}{*}{ Succinic acid } & Between groups & 2 & 0.068 & \multirow{3}{*}{7.876} & \multirow{3}{*}{0.002} \\
\hline & Within groups & 26 & 0.009 & & \\
\hline & Total & 28 & & & \\
\hline \multirow{3}{*}{ Malic acid } & Between groups & 2 & 0.346 & \multirow{3}{*}{8.336} & \multirow{3}{*}{0.002} \\
\hline & Within groups & 26 & 0.042 & & \\
\hline & Total & 28 & & & \\
\hline \multirow{3}{*}{ L-ascorbic acid } & Between groups & 2 & 0.45 & \multirow{3}{*}{5.927} & \multirow{3}{*}{0.008} \\
\hline & Within groups & 26 & 0.076 & & \\
\hline & Total & 28 & & & \\
\hline
\end{tabular}

TABle 4: Duncan's test results.

\begin{tabular}{lcccccrrr}
\hline \multirow{2}{*}{ Groups } & \multicolumn{2}{c}{ Total phenol } & \multicolumn{2}{c}{ Succinic acid } & \multicolumn{2}{c}{ Malic acid } & \multicolumn{2}{c}{ L-ascorbic acid } \\
& 1 & 2 & 1 & 2 & 1 & 2 & 0.1436 \\
Fresh & 74.7456 & & 0.0266 & & & 0.4024 & 0.1864 \\
Sun-dried & & 229.2815 & 0.0452 & & & 0.5192 & 0.6076 \\
Oven-dried & & 248.4450 & & 0.1795 & & 0.5036 \\
Sig. & 1.000 & 0.719 & 0.664 & 1.000 & 1.000 & 0.219 & 1.000 \\
\hline
\end{tabular}

Means for groups in homogeneous subsets are displayed. a: uses harmonic mean sample size $=9,643$. b: the group sizes are unequal. The harmonic mean of the group sizes is used. The subset for alpha $=0.05$. 
TABLe 5: Kruskal-Wallis $\mathrm{H}$ test results.

\begin{tabular}{lcccccccc}
\hline & \% DPPH inhibition & \% DPPH radical scavenging & Citric acid & Fructose & Glucose & Sucrose & Total sugar & TSS \\
\hline Kruskal-Wallis H & 9.691 & 9.113 & 13.408 & 14.947 & 16.542 & 17.323 & 15.119 & 12.838 \\
df & 2 & 2 & 2 & 2 & 2 & 2 & 2 & 2 \\
Asymp. sig. & 0.008 & 0.010 & 0.001 & 0.001 & 0.000 & 0.000 & 0.001 & 0.002 \\
\hline
\end{tabular}

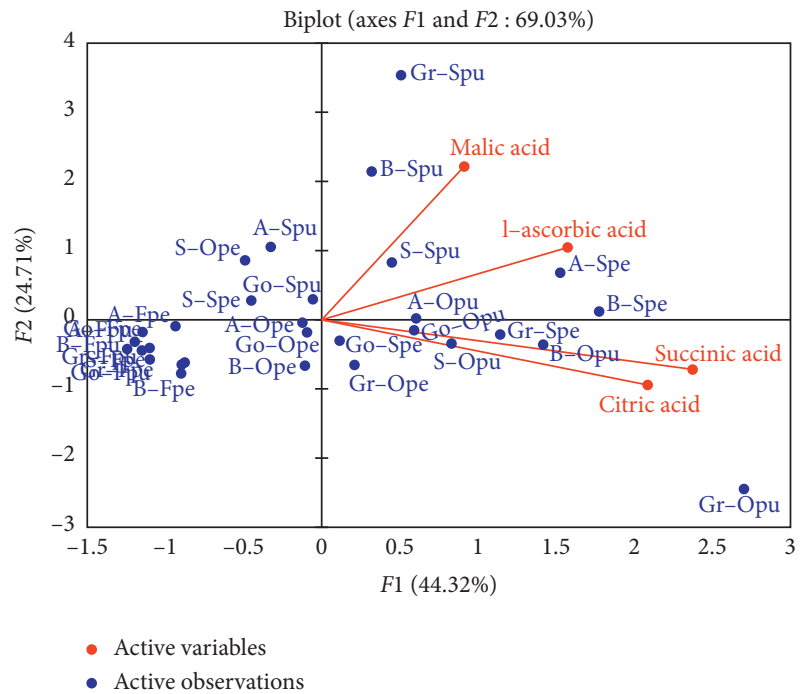

FIGURE 1: Biplot graph of organic acids (scores and loading plots) obtained from principal component analysis (abbreviations; A-Fpe: Amasya fresh peel; A-Fpu: Amasya fresh pulp; A-Ope: Amasya oven-dried peel; A-Opu: Amasya oven-dried pulp; A-Spe: Amasya sun-dried peel; A-Spu: Amasya sun-dried pulp; B: Braeburn; Go: Golden Delicious; Gr: Granny Smith; S: Starking).

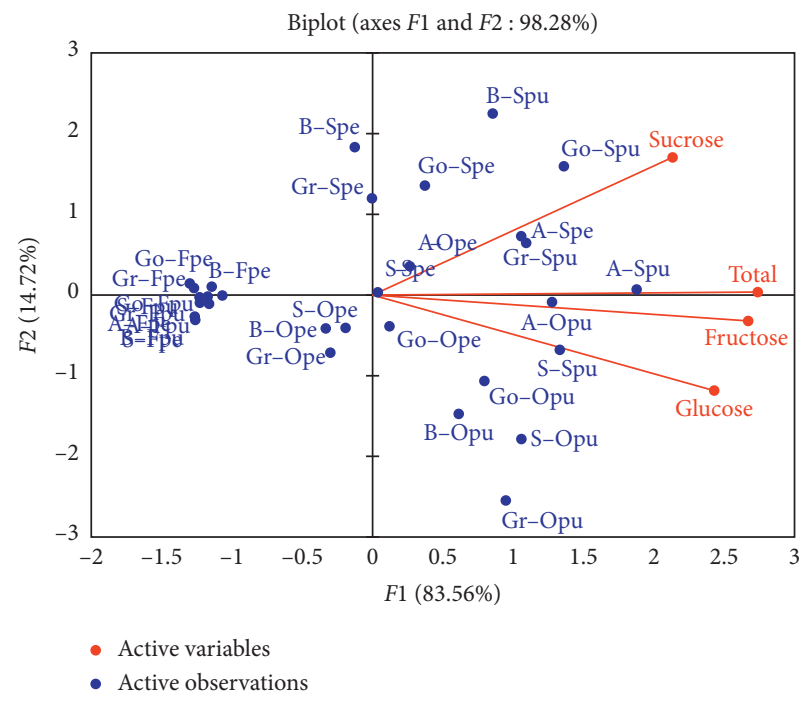

FIgURE 2: Biplot graph of sugars (scores and loading plots) obtained from principal component analysis (abbreviations; A-Fpe: Amasya fresh peel; A-Fpu: Amasya fresh pulp; A-Ope: Amasya oven-dried peel; A-Opu: Amasya oven-dried pulp; A-Spe: Amasya sun-dried peel; A-Spu: Amasya sun-dried pulp; B: Braeburn; Go: Golden Delicious; Gr: Granny Smith; S: Starking). expected. The pulp observations dispersed near to the sugars; however, the peel observations dispersed apart from these sugars.

\section{Conclusions}

Biochemical characteristics are among the inner-quality determiners of fruits, as well as increasing outer quality. Due to their vitality to determine the fruit quality, investigating the biochemical compounds has substantial health and economic importance. In line with that, biochemical compounds of five different apple cultivars (Amasya, Braeburn, Golden Delicious, Granny Smith, and Starking) grown in the same plantation in Isparta were investigated. The novelty of this research comes especially from the investigation of some biochemical compounds through the implementation of different drying methods for the pulp and peel of five different apple varieties. In detail, the total phenol, total flavonoid, sugars, organic acids, TSS, and antioxidants levels were identified and quantified. Amasya oven-dried peel contained the largest level of total flavonoid. The largest total phenol, antioxidant activity, fructose, and total sugar levels were observed in Amasya sun-dried peel. The highest L-ascorbic acid was detected in Amasya oven-dried pulp. Granny Smith oven-dried pulp was rich in citric, succinic acids, and glucose. Braeburn sun-dried pulp, Golden Delicious oven-dried pulp, and Granny Smith sun-dried pulp contained the largest sucrose, malic acid, and total soluble solids levels, respectively. The results provide valuable information on the food quality parameters of five different apple cultivars. Among the organic acids, malic acid was dominant, and among the sugars, the concentration of fructose is much higher than other sugars. Total flavonoid, total phenol, and antioxidant activity parameters are significantly high in the peel. Total phenol, succinic acid, malic acid, and L-ascorbic acid significantly differed among fresh, oven-dried, and sun-dried samples. As is expected, higher sugar levels were observed in the pulp. Moreover, if the cultivar and peel-pulp differences were ignored and the apples were evaluated as a whole, the oven-drying method performed better for total flavonoids, total phenols, and malic acid contents, while the sun-drying method outperformed in terms of antioxidant capacity, fructose, glucose, sucrose, total sugars, TSS, L-ascorbic acid, citric acid, and succinic acid. In light of the results of the research, consuming apple with its peel is healthier. Besides, the effectiveness of fruit drying among the food storage methods was also shown. 


\section{Data Availability}

The data used to support the findings of this study are included within the article.

\section{Conflicts of Interest}

The author declares that there are no conflicts of interest regarding the publication of this paper.

\section{Acknowledgments}

The author thanks Professor Dr. N. Ebru Kafkas for her invaluable support and guidance for this research.

\section{References}

[1] J. Wu, H. Gao, L. Zhao et al., "Chemical compositional characterization of some apple cultivars," Food Chemistry, vol. 103, no. 1, pp. 88-93, 2007.

[2] K. Hecke, K. Herbinger, R. Veberič et al., "Sugar-, acid- and phenol contents in apple cultivars from organic and integrated fruit cultivation," European Journal of Clinical Nutrition, vol. 60, no. 9, pp. 1136-1140, 2006.

[3] S. Rana, S. Kumar, A. Rana, Y. Padwad, and S. Bhushan, "Biological activity of phenolics enriched extracts from industrial apple pomace," Industrial Crops and Products, vol. 160, Article ID 113158, 2021.

[4] E.-I. Geană, C. T. Ciucure, R. E. Ionete et al., "Profiling of phenolic compounds and triterpene acids of twelve apple (Malus domestica borkh.) cultivars," Foods, vol. 10, no. 2, p. 267, 2021.

[5] S. F. Hagen, G. I. A. Borge, G. B. Bengtsson et al., "Phenolic contents and other health and sensory related properties of apple fruit (Malus domestica borkh., cv. aroma): effect of postharvest UV-B irradiation," Postharvest Biology and Technology, vol. 45, no. 1, pp. 1-10, 2007.

[6] J. Boyer and R. H. Liu, "Apple phytochemicals and their health benefits,” Nutrition Journal, vol. 3, no. 5, 2004.

[7] P. Kroon and G. Williamson, "Polyphenols: dietary components with established benefits to health?" Journal of the Science of Food and Agriculture, vol. 85, no. 8, pp. 1239-1240, 2005.

[8] K. Wolfe, X. Wu, and R. H. Liu, "Antioxidant activity of apple peels," Journal of Agricultural and Food Chemistry, vol. 51, no. 3, pp. 609-614, 2003.

[9] G. Campeanu, G. Neata, and G. Darjanschi, "Chemical composition of the fruits of several apple cultivars growth as biological crop," Notulae Botanicae Horti Agrobotanici ClujNapoca, vol. 37, no. 2, pp. 161-164, 2009.

[10] FAO: Food and Agriculture Organization Statistics Division, FAO, Rome, Italy, 2021, http://www.fao.org/faostat/en/\#data/ QC.

[11] M. M. Petkovsek, F. Stampar, and R. Veberic, "Parameters of inner quality of the apple scab resistant and susceptible apple cultivars (Malus domestica borkh.)," Scientia Horticulturae, vol. 114, no. 1, pp. 37-44, 2007.

[12] O. K. Chun, D.-O. Kim, N. Smith, D. Schroeder, J. T. Han, and C. Y. Lee, "Daily consumption of phenolics and total antioxidant capacity from fruit and vegetables in the American diet," Journal of the Science of Food and Agriculture, vol. 85, no. 10, pp. 1715-1724, 2005.

[13] M. Kalinowska, K. Gryko, A. M. Wróblewska, A. JabłońskaTrypuć, and D. Karpowicz, "Phenolic content, chemical composition and anti-/pro-oxidant activity of gold milenium and papierowka apple peel extracts," Scientific Reports, vol. 10, no. 1, 2020.

[14] R. Preti and A. M. Tarola, "Study of polyphenols, antioxidant capacity and minerals for the valorisation of ancient apple cultivars from northeast Italy," European Food Research and Technology, vol. 247, no. 1, pp. 273-283, 2021.

[15] H. K. Yoon, T. Kleiber, Z. Zydlik et al., "A comparison of selected biochemical and physical characteristics and yielding of fruits in apple cultivars (Malus domestica borkh," Agronomy, vol. 10, no. 4, 2020.

[16] K. W. Lee, Y. J. Kim, D.-O. Kim, H. J. Lee, and C. Y. Lee, "Major phenolics in apple and their contribution to the total antioxidant capacity," Journal of Agricultural and Food Chemistry, vol. 51, no. 22, pp. 6516-6520, 2003.

[17] R. Tsao, R. Yang, J. C. Young, and H. Zhu, "Polyphenolic profiles in eight apple cultivars using high-performance liquid chromatography (HPLC)," Journal of Agricultural and Food Chemistry, vol. 51, no. 21, pp. 6347-6353, 2003.

[18] Q. Ma, J. Bi, J. Yi, X. Wu, X. Li, and Y. Zhao, "Stability of phenolic compounds and drying characteristics of apple peel as affected by three drying treatments," Food Science and Human Wellness, vol. 10, no. 2, pp. 174-182, 2021.

[19] U. Imeh and S. Khokhar, "Distribution of conjugated and free phenols in fruits: antioxidant activity and cultivar variations," Journal of Agricultural and Food Chemistry, vol. 50, no. 22, pp. 6301-6306, 2002.

[20] P. D. Drogoudi, Z. Michailidis, and G. Pantelidis, "Peel and flesh antioxidant content and harvest quality characteristics of seven apple cultivars," Scientia Horticulturae, vol. 115, no. 2, pp. 149-153, 2008.

[21] C. Henríquez, S. Almonacid, I. Chiffelle et al., "Determination of antioxidant capacity, total phenolic content and mineral composition of different fruit tissue of five apple cultivars grown in Chile," Chilean Journal of Agricultural Research, vol. 70, no. 4, pp. 523-536, 2010.

[22] M. Manzoor, F. Anwar, N. Saari, and M. Ashraf, "Variations of antioxidant characteristics and mineral contents in pulp and peel of different apple (Malus domestica borkh.) cultivars from Pakistan," Molecules, vol. 17, no. 1, pp. 390-407, 2012.

[23] C. Varming, M. A. Petersen, and T. B. Toldam-Andersen, "Ascorbic acid contents in danish apple cultivars and commercial apple juices," LWT-Food Science and Technology, vol. 54, no. 2, pp. 597-599, 2013.

[24] V. Planchon, M. Lateur, P. Dupont, and G. Lognay, "Ascorbic acid level of belgian apple genetic resources," Scientia Horticulturae (SCI HORTIC-AMSTERDAM), vol. 100, no. 1-4, pp. 51-61, 2004.

[25] F. G. K. Vieira, G. D. S. C. Borges, C. Copetti, R. D. D. M. C. Amboni, F. Denardi, and R. Fett, "Physicochemical and antioxidant properties of six apple cultivars (Malus domestica borkh) grown in southern Brazil," Scientia Horticulturae, vol. 122, no. 3, pp. 421-425, 2009.

[26] C. E. Lister, J. E. Lancaster, K. H. Sutton, and J. R. L. Walker, "Developmental changes in the concentration and composition of flavonoids in skin of a red and a green apple cultivar," Journal of the Science of Food and Agriculture, vol. 64, no. 2, pp. 155-161, 1994.

[27] B. Bozan, Z. Tunalier, M. Koşar, A. Altıntaş, and K. H. C. Başer, "Comparison of ascorbic and citric acid contents in "emphasis type"," in Proceedings of the 11 Symposium Plant Origin Crude Drugs, Ankara, Turkey, 1997.

[28] G. A. Spanos and R. E. Wrolstad, "Influence of processing and storage on the phenolic composition of thompson seedless 
grape juice," Journal of Agricultural and Food Chemistry, vol. 38, no. 7, pp. 1565-1571, 1990.

[29] H. İ. Uzun and A. Bayır, Bazı Şaraplık Üzüm Çeşitlerine Ait Çekirdeklerin Toplam Fenolik Madde Içerikleri Ve Antiradikal Aktivitelerinin Belirlenmesi, Akdeniz University, Antalya, Turkey, 2007.

[30] D. Marinova, F. Ribarova, and M. Atanassova, "Total phenolics and total flavonoids in bulgarian fruits and vegetables," Journal of Chemical Technology and Metallurgy, vol. 40, no. 3, pp. 255-260, 2005.

[31] W. Brand-Williams, M. E. Cuvelier, and C. Berset, "Use of a free radical method to evaluate antioxidant activity," LWT_Food Science and Technology, vol. 28, no. 1, pp. 25-30, 1995.

[32] U. Kohler and M. Luniak, "Data inspection using biplots," The Stata Journal: Promoting Communications on Statistics and Stata, vol. 5, no. 2, pp. 208-223, 2005.

[33] V. Okatan, I. Bulduk, A. Sekara, A. M. Colak, B. Kaki, and M. Gundogdu, "Bioactive components and market quality of apple (Malus $x$ domestica borkh.) fruits could be effectively controlled by trees pretreatment with boric acid, melatonin and gibberellic acid," Fresenius Environ. Bull.vol. 27, no. 10, pp. 6933-6944, 2018.

[34] J. Bizjak, N. Weber, M. Mikulic-Petkovsek et al., "Influence of phostrade $\mathrm{Ca}$ on color development and anthocyanin content of "braeburn" apple (Malus domestica borkh.)," HortScience, vol. 48, no. 2, pp. 193-199, 2013.

[35] A. Güleç, R. Nergiz-Unal, A. Akyol, and J. Acar, "Phenolic content and ascorbic acid are major contributors to antioxidant capacity of fruits and vegetables commonly consumed in Turkey," Journal of Food, Agriculture and Environment, vol. 11, no. 3-4, pp. 463-468, 2013.

[36] J. Jakopic, A. Slatnar, F. Stampar, R. Veberic, and A. Simoncic, "Analysis of selected primary metabolites and phenolic profile of "golden delicious" apples from four production systems," Fruits, vol. 67, no. 5, pp. 377-386, 2012.

[37] M. Morvai and I. Molnár-Perl, "Simultaneous determination of organic acids and sugars in apples by gas-liquid chromatography," Journal of Chromatography A, vol. 520, pp. 201207, 1990.

[38] E. Kafkas, A. Atasay, F. K. Sabir, H. Akgül, and K. Uçgun, "Effects of different irrigation intervals and fertilizer applications on certain chemical contents of "braeburn" apple cultivar," African Journal of Biotechnology, vol. 8, no. 10, pp. 2138-2142, 2009.

[39] F. Karadeniz and A. Ekşi, "Sugar composition of apple juices," European Food Research and Technology, vol. 215, no. 2, pp. 145-148, 2002.

[40] Y. Liu, X. Zhang, and Z. Zhao, "Effects of fruit bagging on anthocyanins, sugars, organic acids, and color properties of "granny smith" and "golden delicious" during fruit maturation," European Food Research and Technology, vol. 236, no. 2, pp. 329-339, 2013.

[41] Y. Ozkan, E. Altuntas, B. Ozturk, K. Yildiz, and O. Saracoglu, "The effect of NAA (1-naphthalene acetic acid) and avg (aminoethoxyvinylglycine) on physical, chemical, colour and mechanical properties of braeburn apple," International Journal of Food Engineering, vol. 8, no. 3, 2012.

[42] B. S. Mpelasoka, M. H. Behboudian, J. Dixon, S. M. Neal, and H. W. Caspari, "Improvement of fruit quality and storage potential of "braeburn" apple through deficit irrigation," The Journal of Horticultural Science and Biotechnology, vol. 75, no. 5, pp. 615-621, 2000.
[43] K. S. Zulkifli, N. Abdullah, A. Abdullah, N. Aziman, and W.S. S. W. Kamarudin, "Bioactive phenolic compounds and antioxidant activity of selected fruit peels," in Proeedings of the 2012 International Conference on Environment, Chemistry and Biology, vol. 49, no. 1, pp. 66-70, IACSIT Press, Singapore, 2012.

[44] L. Montero, M. Herrero, E. Ibáñez, and A. Cifuentes, "Profiling of phenolic compounds from different apple varieties using comprehensive two-dimensional liquid chromatography," Journal of Chromatography A, vol. 1313, pp. 275-283, 2013.

[45] F. G. K. Vieira, G. D. S. C. Borges, C. Copetti, P. F. Di Pietro, E. d. C. Nunes, and R. Fett, "Phenolic compounds and antioxidant activity of the apple flesh and peel of eleven cultivars grown in Brazil," Scientia Horticulturae, vol. 128, no. 3, pp. 261-266, 2011.

[46] I. Fernández-Jalao, C. Sánchez-Moreno, and B. De Ancos, "Effect of high-pressure processing on flavonoids, hydroxycinnamic acids, dihydrochalcones and antioxidant activity of apple "golden delicious" from different geographical origin," Innovative Food Science \& Emerging Technologies, vol. 51, pp. 20-31, 2019. 